\title{
Level of awareness of oral cancer and oral potentially malignant disorders among medical and dental undergraduates
}

\author{
R D Jayasinghe ${ }^{1}$, L P G Sherminie ${ }^{2}$, H Amarasinghe ${ }^{3}$, M A M Sitheeque ${ }^{1}$ \\ (Index words: oro-pharyngial cancer, medical education, Sri Lanka, Asia)
}

\begin{abstract}
The aim of this study was to investigate the awareness of oral potentially malignant disorders (OPMD) and oral cancer among medical and dental students of the University of Peradeniya. A pre-tested, self-administered questionnaire was used among 1006 students. Majority were medical students (74.3\%), females (60.5\%), and in the second year (25.2\%). About $54 \%$ of respondents had poor knowledge. Dental students had a significantly higher knowledge and female students showed greater awareness. About $90 \%$ of medical students had never examined a patient with OPMD, and $79.5 \%$ of them had not examined one with oral cancer. Medical undergraduates must receive adequate education about OPMD and cancer.
\end{abstract}

Ceylon Medical Journal 2016; 61: 77-79

DOI: http://doi.org/10.4038/cmj.v61i2.8289

\section{Introduction}

Oral cancer (OCA) accounts for $12.8 \%$ of all cancers in Sri Lanka [1]. Most commonly it occurs in middle-aged and older individuals. It is the commonest cancer among men, and accounts for $18.4 \%$ of all male cancers [1]. Incidence among females is $4.82 \%$ [1]. It is a significant health problem in Sri Lanka since it accounts for 9.3\% deaths of all cancers in both sexes [1].

Common signs and symptoms of oral cancers are an ulcer in the mouth that does not heal, pain that does not go away, a lump in the cheek, a white or red patch in the mouth, and sore throat and difficulty in chewing or swallowing. OCA is associated with betel chewing with or without tobacco, smoking, alcohol consumption, infection with human papilloma virus, low intake of fruits and vegetables, and long term exposure to sunlight [2].
The stage of diagnosis is important for survival. Oral cancers have a high likelihood of cure when detected at an early stage [3]. Any delay in presentation for treatment might lead to significant morbidity and mortality associated with oral cancer. In most patients with oral cancer, the cancer is preceded by the existence of oral potentially malignant disorders, and when such disorders are diagnosed and managed in an appropriate manner, oral cancer could be prevented. The lack of public awareness concerning oral cancer and oral potentially malignant disorders (OPMD) is an important reason for late detection of these conditions $[4,5]$. Screening programmes help to detect cases of cancer as well as OPMDs [6]. Previous studies reveal that medical and dental practitioners are not fully aware of the importance of routine oral examination, risk factors, and oral potentially malignant disorders [7, 8].

Delay in identification by health professionals is a factor that contributes to delay in the diagnosis of OCA. A study in Pakistan has shown poor level of awareness regarding oral cancer among undergraduate dental students [9]. Literature has highlighted the need for improved education of health professionals at the undergraduate level regarding oral cancer. Published data on awareness among Sri Lankan undergraduates are not available. The general objective of the study was to assess the level of knowledge on OPMD and oral cancer among medical and dental undergraduates in Sri Lanka. The specific objectives were to assess the awareness of burden, associated risk factors, early detection, treatment and prognosis of oral cancer and OPMD.

\section{Methods}

This study was carried out among medical and dental undergraduates at the University of Peradeniya, Sri Lanka

${ }^{1}$ Department of Oral Medicine and Periodontology, Faculty of Dental Sciences, ${ }^{2}$ Department of Radiography/ Radiotherapy, Faculty of Allied Health Sciences, University of Peradeniya and ${ }^{3}$ National Cancer Control Programme, Ministry of Health, Sri Lanka.

Correspondence: RDJ, e-mail: <ruwanja@pdn.ac.lk>. Received 15 October 2015 and revised version accepted 22 December 2015.

This is an open-access article distributed under the terms of the Creative Commons Attribution License, which permits unrestricted use, distribution, and reproduction in any medium, provided the original author and source are credited. 
in 2014. All students at the Faculties of Medicine and Dental Sciences, University of Peradeniya were included in the study. A self-administered questionnaire was used as the data collection tool. It had two parts: the first part gathered socio-demographic characteristics including participants' age, sex, Faculty, and the year of study. Specific questions on OPMD and oral cancer awareness were included in the second part. Written consent for participation was obtained from all participants. Questionnaires were given to the students after a routine lecture. Approval for the study was obtained from the Ethics Review Committee of the Faculty of Dental Sciences, University of Peradeniya. Collected data were computed on ms Excel. SPSS version 17 was used for the statistical analysis.

\section{Results}

One thousand and six students participated in the study out of which 748 (74.3\%) were medical students. Non-response rate was less than $10 \%$. Majority of the participants were females (60.5\%) and were in the second (25.2\%) or third year (22.3\%).

OCA was not identified as the most common cancer among Sri Lankan males by about one half of the respondents. Squamous cell carcinoma was identified correctly as the commonest type of OCA by about $90 \%$ of dental students but only by $34.5 \%$ medical students. The participants had a good understanding about the aetiological agents of OPMD and oral cancer. Chewing betel with tobacco and arecanut as a cause of oral cancer was identified correctly by $95.2 \%$ of the respondents and $93.8 \%$ of them identified the role of smoking correctly. Only $29 \%$ of the medical students were aware of oral submucous fibrosis (Table 1). Overall, dental students had a better knowledge than the medical students $(p<0.01)$.

Participants' awareness on OPMD was poor. Only 36\% identified oral leukoplakia as an OPMD. About a third of participants believed that the early detection of oral cancer was difficult. Knowledge of treatment options was not adequate among the respondents. Only $11 \%$ of the respondents knew the overall 5-year survival rate of oral cancer. Only $10.7 \%$ of the respondents had good knowledge of OPMD and oral cancer and in $12.5 \%$ of them, knowledge was very poor. Dental students and medical students in the final year had significantly better knowledge $(p<0.05)$. Senior students in the years 3, 4 and 5 had better knowledge than the junior students $(p<0.01)$. Of the medical students $80.9 \%$ had not examined a patient with OPMD and $79.5 \%$ of them had not examined an oral cancer (Table 2).

Table 1. Awareness on burden and behevioural characteristics, risk factors, early detection and prevention of $\mathrm{OCA}$

\begin{tabular}{|c|c|c|c|c|c|c|}
\hline & \multicolumn{6}{|c|}{ Answered correctly } \\
\hline & $\begin{array}{l}\text { Medical } \\
\mathrm{N}\end{array}$ & $\begin{array}{c}(748) \\
\%\end{array}$ & $\begin{array}{l}\text { Dental } \\
\mathrm{N}\end{array}$ & $\begin{array}{c}(258) \\
\%\end{array}$ & $\begin{array}{l}\text { Total } \\
\mathrm{N}\end{array}$ & $\begin{array}{c}(1006) \\
\%\end{array}$ \\
\hline $\begin{array}{l}\text { OCA is the most common cancer among } \\
\text { Sri Lankan men }\end{array}$ & 341 & 45.8 & 147 & 57 & 488 & 48.5 \\
\hline OCA affects higher socioeconomic groups & 568 & 75.9 & 201 & 77.9 & 769 & 76.4 \\
\hline $\begin{array}{l}\text { Commonest type of OCA is squamous } \\
\text { cell carcinoma }\end{array}$ & 258 & 34.5 & 234 & 90.7 & 492 & 48.9 \\
\hline $\begin{array}{l}\text { OCA is mostly a non-preventable disease } \\
\text { in Sri Lanka }\end{array}$ & 561 & 75 & 221 & 85.7 & 782 & 77.7 \\
\hline $\begin{array}{l}\text { Chewing betel quid with tobacco and areca } \\
\text { nut is a cause of OCA }\end{array}$ & 705 & 94.3 & 254 & 98.4 & 959 & 95.3 \\
\hline $\begin{array}{l}\text { Smoking does not play any role in the } \\
\text { causation of oral cancer }\end{array}$ & 702 & 93.9 & 242 & 93.8 & 944 & 93.8 \\
\hline Areca nut induced OSF is an OPMD & 216 & 28.9 & 190 & 73.6 & 406 & 40.4 \\
\hline $\begin{array}{l}\text { Excessive alcohol consumption is } \\
\text { a causative factor for oral cancer }\end{array}$ & 379 & 50.7 & 146 & 56.6 & 525 & 52.2 \\
\hline $\begin{array}{l}\text { OCA is mostly preceded by white or red } \\
\text { patches in the oral mucosa }\end{array}$ & 495 & 66.2 & 211 & 81.8 & 706 & 70.2 \\
\hline Oral leukoplakia is a OPMD & 201 & 26.9 & 161 & 62.4 & 362 & 36 \\
\hline OPMD will always progress to malignancy & 297 & 39.7 & 180 & 69.8 & 477 & 47.4 \\
\hline Early detection of oral cancer is difficult & 492 & 65.8 & 199 & 77.1 & 691 & 68.7 \\
\hline $\begin{array}{l}\text { Cancer of the floor of the mouth has } \\
\text { a poor prognosis. }\end{array}$ & 174 & 23.3 & 102 & 39.5 & 276 & 27.4 \\
\hline Overall 5-year survival rate <70\%. & 75 & 10 & 36 & 14 & 111 & 11 \\
\hline $\begin{array}{l}\text { Radiotherapy alone is the best method of } \\
\text { treatment for advanced oral cancer }\end{array}$ & 297 & 39.7 & 175 & 67.8 & 472 & 46.9 \\
\hline
\end{tabular}


Table 2. Participants' clinical exposure to oral cancer during undergraduate training

\begin{tabular}{|c|c|c|c|c|c|c|}
\hline & $\begin{array}{l}\text { Medical } \\
\mathrm{N}\end{array}$ & $\begin{array}{c}(748) \\
\%\end{array}$ & $\begin{array}{l}\text { Dental } \\
\mathrm{N}\end{array}$ & $\begin{array}{c}(258) \\
\%\end{array}$ & $\begin{array}{l}\text { Total } \\
\mathrm{N}\end{array}$ & $\begin{array}{c}(1006) \\
\%\end{array}$ \\
\hline Examined a patient with OPMD & 93 & 605 & 50 & 126 & 121 & 11 \\
\hline Examined a patient with oral cancer & 114 & 595 & 38 & 138 & 110 & 10 \\
\hline Assisted a biopsy & 15 & 690 & 43 & 49 & 198 & 11 \\
\hline $\begin{array}{l}\text { Sufficient knowledge on prevention and } \\
\text { detection of OPMD/ oral cancer }\end{array}$ & 63 & 640 & 44 & 72 & 174 & 12 \\
\hline
\end{tabular}

\section{Discussion}

Medical and dental undergraduates who participated in this study had a good understanding of the aetiological agents of OPMD and oral cancer. However, identification of alcohol as a potential risk for oral carcinogenesis was low (47.8\%). In contrast to the published literature, where the identification of alcohol as a risk factor is high among dental students in this study, only $43.4 \%$ of dental students in this study identified it correctly, whereas among medical students it was higher (49.3\%) [8]. This shows the importance of emphasising the role of alcohol in causation of oral cancer in teaching curricula.

Even though they had a good knowledge of some OPMDs, oral erythroplakia as an OPMD was identified correctly only by $18.3 \%$ of the respondents. Low awareness of erythroplakia as an OPMD has been reported by others as well [8]. Only 11\% knew the overall 5-year survival rate of oral cancer. Knowledge of OPMD and oral cancer among the participants was not satisfactory, and only $10.7 \%$ of the respondents had good knowledge of OPMD and oral cancer, and in $12.5 \%$, it was very poor. Similar to the literature from other countries, dental students, especially students in the final year, had a significantly better knowledge $(p<0.05)$ [10].

About $80 \%$ of the medical students had not examined an OPMD or a single oral cancer. A significant number of medical and dental students who have completed clinical training believe that they do not have sufficient knowledge on prevention and detection of OPMD and oral cancer. In a country where OPMD and oral cancers are common, this emphasizes the need for a change in the medical curriculum to incorporate this important area.

\section{Conflicts of interests}

There are no conflicts of interest.

\section{References}

1. National Cancer Control Programme Sri Lanka: Cancer Incidence Data: Sri Lanka Year 2008. Colombo: NCCP, 2015.

2. Warnakulasuriya S. Causes of oral cancer - an appraisal of controversies Br Dent J 2009; 207: 471-5.

3. Silverman S Jr. Early Diagnosis of Oral Cancer. Cancer 1988; 62: 1796-9.

4. Warnakulasuriya KAAS, Haris CK, Scarrot DM, et al. An alarming lack of public awareness towards oral cancer $\mathrm{Br}$ Dent J 1999; 187: 319-22.

5. Amarasinghe HK, Usgidaarachchi US, Johnson NW, Lalloo $\mathrm{R}$, Warnakulasuriya S. Public awareness of oral cancer, of oral potentially malignant disorders and of their risk factors in some rural population in Sri Lanka. Community Dent Oral Epidemiol 2010; 38; 540-8.

6. Nagao T, Warnakulasuriya S. Annual screening for oral cancer detection. Cancer Detect Prev 2003; 27: 333-7.

7. Macpherson LMD, McCann MF, Gibson F, Binnie VI, Stephen KW. The role of primary healthcare professionals in oral cancer prevention and detection. Br Dent J 2003; 195: 277-81.

8. Carter LM, Ogden GR. Oral cancer awareness of general medical and general dental practitioners. Br Dent J 2007; 9: 4.

9. Kazmi F, Chaudhary MA, Mumtaz M, Bhatti MUD, Khawaja N. Oral cancer knowledge and awareness amongst undergraduate dental students of Lahore-Pakistan. Pak Oral Dent J 2011; 31: 64-7.

10. Sitheeque M, Ahmad Z, Saini R. Awareness of oral cancer and precancer among final year medical and dental students of Universiti Sains Malaysia (USM), Malaysia. Arch Orofac Sci 2014; 9: 53-64. 